Submit to: Surface Science

Date: January 12, 2015

\title{
Reaction Pathways of Model Compounds of Biomass-Derived Oxygenates on Fe/Ni Bimetallic Surfaces
}

\author{
Weiting Yu, Jingguang G. Chen ${ }^{*}$ \\ Department of Chemical Engineering, Columbia University, New York, NY, 10027
}

*Corresponding author, jgchen@columbia.edu 
Abstract

Controlling the activity and selectivity of converting biomass-derivatives to fuels and valuable chemicals is critical for the utilization of biomass feedstocks. There are primarily three classes of non-food competing biomass, cellulose, hemicellulose and lignin. In the current work, glycolaldehyde, furfural and acetaldehyde are studied as model compounds of the three classes of biomass-derivatives. Monometallic $\mathrm{Ni}(111)$ and monolayer (ML) Fe/Ni(111) bimetallic surfaces are studied for the reaction pathways of the three biomass surrogates. The ML $\mathrm{Fe} / \mathrm{Ni}(111)$ surface is identified as an efficient surface for the conversion of biomass-derivatives from the combined results of density functional theory (DFT) calculations and temperature programmed desorption (TPD) experiments. A correlation is also established between the optimized adsorption geometry and experimental reaction pathways. These results should provide helpful insights in catalyst design for the upgrading and conversion of biomass.

Keywords:

Bimetallic surfaces; ML Fe/Ni(111) surface; biomass-derivatives; furfural; glycolaldehyde; acetaldehyde; 


\section{Introduction}

The declining supply of fossil fuel resources and the increasing energy demand by the rapidly developing economies lead to the imperative development of sustainable energy. Nonfood competing biomass, due to its advantages of being abundantly available, renewable and potentially carbon-neutral, is regarded as an alternative energy source to fossil fuels. There are three main classes of non-food competing biomass, which are cellulose, hemicellulose and lignin [1]. It is critical to study the conversion of the three types of biomass resources for the production of valuable chemicals and bio-fuels. However, the low vapor pressure and high molecular weight of large biomass-derivatives bring difficulty into fundamental surface science studies using ultrahigh vacuum (UHV) techniques. Therefore it is important to identify smaller molecules as the model compounds in the surface science study of biomass conversion.

Glucose is produced from cellulose through the hydrolysis process. The key functionalities of glucose are the $\mathrm{C}-\mathrm{OH}$ and $\mathrm{C}=\mathrm{O}$ groups. Therefore glycolaldehyde $\left(\mathrm{HOCH}_{2} \mathrm{CH}=\mathrm{O}\right)$, the smallest molecule that contains both $\mathrm{C}-\mathrm{OH}$ and $\mathrm{C}=\mathrm{O}$ bonds as well as the same $\mathrm{C} / \mathrm{O}$ ratio as glucose, is selected as a probe compound of cellulosic biomass [2]. Furthermore, according to the literature [3], the contents of glycolaldehyde and aldehydes are as high as $20 \%$ in the crude bio-oil from the pyrolysis of lignin biomass. Furfural [4], produced by the hydrolysis and dehydration of hemicellulose, is considered as a model compound of biomassderivatives from hemicellulosic biomass. Thus, glycolaldehyde, acetaldehyde and furfural are useful surrogate molecules for the reaction pathways of biomass conversion in DFT and UHV surface science studies. One of the reaction pathways for glycolaldehyde and acetaldehyde is the reforming pathway to produce syngas, which can be used in Fischer-Tropsch [5], water gas shift $[6,7]$ and methanol synthesis [8] processes. A desirable conversion pathway of furfural is to 
produce an important biofuel, 2-methylfuran, through the hydrodeoxygenation (HDO) reaction to remove the oxygen atom in the carbonyl group with the furan ring remaining intact [4].

Previously, as an example of using small alcohols and polyols as the model compounds of biomass, the aqueous-phase reforming of ethylene glycol was compared over different transition metals [9], Pt and $\mathrm{Ni}$ were identified as promising monometallic catalysts for the reforming of small oxygenates with both high activity and $\mathrm{H}_{2}$ selectivity. Bimetallic surfaces and catalysts are known to often exhibit unique properties different from either of the parent metals [10-15] and therefore the Ni/Pt bimetallic catalyst has been extensively studied for small oxygenates. For example, Ni-modified Pt(111) bimetallic surfaces have been studied for the reforming of glycolaldehyde [2], and the monolayer (ML) Ni/Pt(111) surface [16] has been identified to show a higher reforming activity than $\mathrm{Ni}(111)$ and $\mathrm{Pt}(111)$ monometallic surfaces. However, $\mathrm{Pt}$ is expensive and scarce, and therefore non-precious metal $\mathrm{Ni}(111)$ is employed to replace $\mathrm{Pt}(111)$ as the substrate in the study. Recently, Resasco and the co-workers also studied the furfural reaction on $\mathrm{SiO}_{2}$-supported $\mathrm{Ni}$ [17] and $\mathrm{Fe} / \mathrm{Ni}$ [18] catalysts. Therefore, in the current study $\mathrm{Ni}(111)$ and $\mathrm{ML} \mathrm{Fe} / \mathrm{Ni}(111)$ surfaces are investigated for the reaction pathways of glycolaldehyde, acetaldehyde and furfural molecules via a combination of DFT calculations and temperature programmed desorption (TPD) experiments for the feasibility of using non-precious monometallic and bimetallic surfaces for biomass conversion.

2. Theoretical and Experimental Methods

\subsection{DFT Calculations}

All DFT calculations were performed with the Vienna Ab initio Simulation Package (VASP) [19-22] and the PW 91 functional [23] was used in the generalized gradient 
approximation (GGA) [24] calculation. A kinetic cutoff energy of $396 \mathrm{eV}$ was chosen for the plane wave truncation. All slab calculations were performed with a $3 \times 3 \times 1$ Monkhorst-Pack kpoint grid. The clean $\mathrm{Ni}(111)$ surface was modeled by adding six equivalent layers of vacuum onto four Ni layers, in which the two bottom layers of the Ni(111) slab were frozen at a metal

distance of $2.49 \AA$, while the top two layers were allowed to relax to reach the lowest energy configuration. The monolayer (ML) Fe/Ni(111) surface was modeled by replacing the $\mathrm{Ni}$ atoms in the top layer with $\mathrm{Fe}$ atoms. The calculations on $\mathrm{Ni}(111)$ and $\mathrm{ML} \mathrm{Fe} / \mathrm{Ni}(111)$ surfaces were performed with spin-polarization. The binding energies of glycolaldehyde, acetaldehyde and furfural were calculated on each surface by subtracting the energies of the bare slab and free molecule from the total energy of the slab plus the corresponding adsorbed molecule. The optimized adsorption configurations of glycolaldehyde, acetaldehyde and furfural on the ML $\mathrm{Fe} / \mathrm{Ni}(111)$ surface are shown in Figure 1. A periodic $4 \times 4$ unit cell was used in the calculation for furfural to reduce the interaction between the molecules, while a $3 \times 3$ unit cell was used for the two smaller molecules. The adsorption coverage is $1 / 16$ (molecule/metal atom) for furfural and 1/9 (molecule/metal atom) for glycolaldehyde and acetaldehyde.

\subsection{Surface Science Experiments}

Glycolaldehyde (Fisher scientific, 98\%, dimer), acetaldehyde (Sigma-Aldrich, 99.85\%) and furfural (Sigma Aldrich, 99\%) were transferred into glass sample cylinders separately. Glycolaldehyde was purified using repeated heat-pump-cool cycles, while acetaldehyde and furfural samples were purified using freeze-pump-thaw cycles. All other gases, oxygen, hydrogen, neon, propylene and carbon monoxide were of research purity and were used without further purification. The purity of all the reagents were verified before experiments using mass 
spectrometry. The glycolaldehyde sample was preheated to $330 \mathrm{~K}$ and dosed to the UHV system through a stainless steel dosing tube approximately $10 \mathrm{~cm}$ away from crystal surface. The furfural and acetaldehyde sample were dosed with the liquid samples at room temperature.

The TPD measurements were performed in a UHV chamber with a base pressure of $1 \mathrm{x}$ $10^{-10}$ Torr, equipped with a mass spectrometer, an Auger electron spectrometer (AES), a sputter gun and an Fe source, as described previously [25]. A Ni(111) single crystal (Princeton Scientific, $99.99 \%, 2 \mathrm{~mm}$ thick and $10 \mathrm{~mm}$ in diameter) was placed at the center of the UHV chamber by directly spot-welding to two tantalum posts, allowing resistive heating and cooling with liquid nitrogen. A chromel-alumel K type thermocouple was welded onto the back of the Ni sample for temperature measurement. The $\mathrm{Ni}(111)$ surface was cleaned using cycles of sputtering in neon followed by annealing at $1100 \mathrm{~K}$. Based on previous work using AES [26], LEED and STM [27], the growth of $\mathrm{Fe}$ on $\mathrm{Ni}(111)$ followed a layer-by-layer growth mechanism. The ML Fe/Ni(111) bimetallic surface was prepared using physical vapor deposition when the $\mathrm{Ni}(111)$ surface temperature was held at $300 \mathrm{~K}$. The amount of Fe on the surface was controlled by the current of the Fe metal source and the deposition time. After deposition, the composition of the ML $\mathrm{Fe} / \mathrm{Ni}(111)$ surface was estimated using the AES method described previously [28]. The relative Auger intensity ratio $\left(\mathrm{I}_{\mathrm{Fe}} / \mathrm{I}_{\mathrm{Ni}}\right)$ for the ML Fe/Ni(111) surface is around 0.15 [29].

\section{Results and Discussion}

\subsection{DFT Calculation Results}

DFT calculations were performed for the three types of biomass-derivatives, glycolaldehyde, acetaldehyde and furfural, on $\mathrm{Ni}(111)$ and $\mathrm{ML} \mathrm{Fe} / \mathrm{Ni}(111)$ surfaces. Figure 1 shows the top and side views of the optimized adsorption configurations of the three molecules 
on the ML Fe/Ni(111) surface. The binding energies, as well as the bond lengths in glycolaldehyde, acetaldehyde and furfural in gas phase and adsorbed configurations on Ni(111) and ML Fe/Ni(111) surfaces are summarized in Table 1. Due to the complex structure, the carbon and oxygen atoms in furfural are numbered in the molecular structure shown in Table 1.

As shown in Figure 1, glycolaldehyde is bonded onto the ML Fe/Ni(111) surface through both the $\mathrm{C}=\mathrm{O}$ and $\mathrm{C}-\mathrm{O}$ functional groups, leading to an increase in the $\mathrm{C}=\mathrm{O}$ and $\mathrm{C}-\mathrm{O}$ bond lengths in Table 1. The adsorption of acetaldehyde onto the ML Fe/Ni(111) surface is through the carbonyl group in an $\eta 2(\mathrm{C}, \mathrm{O})$ configuration, which agrees well with the increase in the $\mathrm{C}=\mathrm{O}$ bond length. Furfural adsorbs onto the ML Fe/Ni(111) surface through both the furan ring and the carbonyl group, consistent with the bond length increase in the corresponding functional groups after adsorption. For example, compared with the gas phase, the bond lengths of C1-O1 in the carbonyl group and $\mathrm{C} 3-\mathrm{C} 4$ in the furan ring increase when furfural is adsorbed on the ML Fe/Ni(111) surface.

As shown in Table 1, for all three molecules, the binding energies are larger on the ML $\mathrm{Fe} / \mathrm{Ni}(111)$ surface than clean $\mathrm{Ni}(111)$, indicating that the addition of the Fe layer binds the molecules more strongly. Furthermore, compared with those on Ni(111), the bond lengths in the molecules on the ML Fe/Ni(111) surface are generally longer due to the stronger interaction between the molecule and the surface. However, exceptions are found for the $\mathrm{C}-\mathrm{C}$ bond lengths in glycolaldehyde and acetaldehyde as well as the C1-C2 bond length in furfural. The decrease in the $\mathrm{C}-\mathrm{C}$ bond lengths in the three molecules on the ML Fe/Ni(111) surface can be correlated with the $\mathrm{C}-\mathrm{C}$ bond scission activity, as discussed next. 


\subsection{TPD Experiments of Glycolaldehyde on Fe/Ni(111) Surfaces}

There are three possible net reaction pathways of glycolaldehyde: (1) the total decomposition pathway, (2) the reforming pathway and (3) the deoxygenation pathway.

$$
\begin{aligned}
& \mathrm{a} \mathrm{HOCH} \mathrm{H}_{2} \mathrm{CHO} \rightarrow 2 \mathrm{a} \mathrm{C}_{a d}+2 \mathrm{a} \mathrm{O}_{a d}+2 \mathrm{a} \mathrm{H}_{2} \text { (Total decomposition) } \\
& \mathrm{b} \mathrm{HOCH} \mathrm{H}_{2} \mathrm{CHO} \rightarrow 2 \mathrm{~b} \mathrm{CO}+2 \mathrm{~b} \mathrm{H}_{2} \text { (Reforming) } \\
& \mathrm{c} \mathrm{HOCH}_{2} \mathrm{CHO} \rightarrow \mathrm{c} \mathrm{C}_{2} \mathrm{H}_{4}+2 \mathrm{cO}_{a d} \text { (Deoxygenation) }
\end{aligned}
$$

Figure 2 displays the TPD spectra of hydrogen $(\mathrm{m} / \mathrm{e}=2)$ and carbon monoxide $(\mathrm{m} / \mathrm{e}=28)$ from $\mathrm{Ni}(111)$ and ML Fe/Ni(111) surfaces after an exposure of 4 L glycolaldehyde. In Figure 2a, the decomposition of glycolaldehyde leads to the desorption of $\mathrm{H}_{2}$ at $345 \mathrm{~K}$ from the $\mathrm{Ni}(111)$ surface, as well as $340 \mathrm{~K}$ and $410 \mathrm{~K}$ from the $\mathrm{ML} \mathrm{Fe} / \mathrm{Ni}(111)$ surface. In Figure $2 \mathrm{~b}$, the desorption peaks of the $\mathrm{CO}$ product are observed at $420 \mathrm{~K}$ from $\mathrm{Ni}(111)$ and $415 \mathrm{~K}$ from $\mathrm{ML}$ $\mathrm{Fe} / \mathrm{Ni}(111)$. There is no desorption peak observed at $\mathrm{m} / \mathrm{e}=26$ and $\mathrm{m} / \mathrm{e}=27$ (not shown), indicating that the deoxygenation pathway to produce ethylene does not occur on $\mathrm{Ni}(111)$ or ML $\mathrm{Fe} / \mathrm{Ni}(111)$. The chemisorbed glycolaldehyde on the two surfaces undergoes the total decomposition and reforming pathways.

The activity of glycolaldehyde following each reaction pathway on $\mathrm{Ni}(111)$ and $\mathrm{ML}$ $\mathrm{Fe} / \mathrm{Ni}(111)$ surfaces are summarized in Table 2. The literature saturation coverages of $\mathrm{H}_{2}(1 \mathrm{ML}$ [30]) and $\mathrm{CO}(0.5 \mathrm{ML}$ [31]) on $\mathrm{Ni}(111)$ were used for the quantification of the reaction pathways of glycolaldehyde as well as acetaldehyde and furfural discussed later. The details about the quantification method were described previously [2]. The Ni(111) surface shows a higher reforming activity (0.146) and total activity (0.193). Compared with the clean Ni(111) surface, 
the addition of $\mathrm{Fe}$ atoms on the surface leads to a decrease in the reforming activity, consistent with the shorter C-C bond length from the DFT results (Table 1).

\subsection{TPD Experiments of Acetaldehyde on Fe/Ni(111) Surfaces}

As demonstrated in previous studies on the Ni/WC surface [32], possible net reaction pathways of acetaldehyde can be summarized as follows: (4) the total decomposition pathway, (5) the reforming pathway, (6) the deoxygenation reaction pathway and (7) the decarbonylation pathway.

$$
\begin{aligned}
& a \mathrm{CH}_{3} \mathrm{CHO}->2 a \mathrm{C}_{(\mathrm{ad})}+a \mathrm{O}_{(\mathrm{ad})}+2 a \mathrm{H}_{2} \text { (Total decomposition) } \\
& b \mathrm{CH}_{3} \mathrm{CHO}->b \mathrm{CO}+b \mathrm{C}_{(\mathrm{ad})}+2 b \mathrm{H}_{2} \text { (Reforming) } \\
& c \mathrm{CH}_{3} \mathrm{CHO}->c \mathrm{C}_{2} \mathrm{H}_{4}+c \mathrm{O}_{(\mathrm{ad})} \text { (Deoxygenation) } \\
& d \mathrm{CH}_{3} \mathrm{CHO}-->d \mathrm{CH}_{4}+d \mathrm{CO} \text { (Decarbonylation) }
\end{aligned}
$$

Figure 3 displays the TPD spectra of (a) $\mathrm{H}_{2}$ and (b) $\mathrm{CO}$ after dosing 4L acetaldehyde on $\mathrm{Ni}(111)$ and $\mathrm{ML} \mathrm{Fe} / \mathrm{Ni}(111)$ surfaces. Figure 3a shows that $\mathrm{H}_{2}$ is produced from the $\mathrm{Ni}(111)$ surface and the ML Fe/Ni(111) surface at $365 \mathrm{~K}$ and $390 \mathrm{~K}$, with a broader hydrogen desorption peak being observed on ML Fe/Ni(111) than on Ni(111). In Figure 3b, the CO product desorbs from the $\mathrm{Ni}(111)$ surface at $430 \mathrm{~K}$ and the $\mathrm{ML}$ Fe/Ni(111) surface at $415 \mathrm{~K}$. The desorption peak of ethylene or methane is not observed (not shown).

The detection of the $\mathrm{H}_{2}$ and $\mathrm{CO}$ products indicates that chemisorbed acetaldehyde follows the total decomposition and reforming pathways on $\mathrm{Ni}(111)$ and $\mathrm{ML} \mathrm{Fe} / \mathrm{Ni}(111)$ surfaces. As compared in the quantification results summarized in Table 2, the clean Ni(111) surface displays higher reforming activity (0.157) and total activity (0.162). The ML Fe/Ni(111) surface shows lower reforming activity for acetaldehyde, similar with the results of glycolaldehyde. 


\subsection{TPD Experiments of Furfural on Fe/Ni(111) Surfaces}

The mechanism of furfural reaction on hydrogen pre-dosed Fe/Ni(111) surfaces has been published previously [29]. The results of furfural on clean Ni(111) and ML Fe/Ni(111) surfaces are presented here to draw a comparison with C2 oxygenates, glycolaldehyde and acetaldehyde. As summarized previously [29], there are five possible reaction pathways of furfural on Fe/Ni(111) surfaces: (8) total decomposition, (9) reforming, (10) deoxygenation, (11) decarbonylation to produce propylene and (12) hydrogenation. Reaction (10) is the desirable pathway to produce 2-methylfuran via $\mathrm{C}-\mathrm{O}$ bond scission in the carbonyl group with the furan ring intact.

a<smiles>O=Cc1ccco1</smiles>

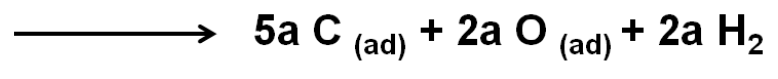

b<smiles>O=Cc1ccco1</smiles>

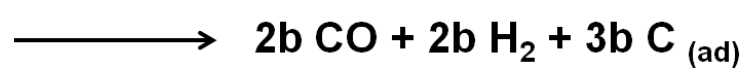

c

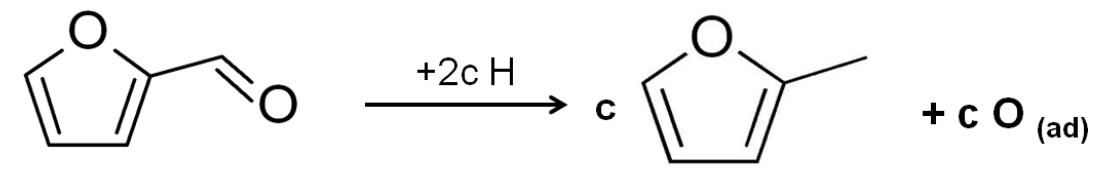<smiles>O=Cc1ccco1</smiles>

$\stackrel{+2 \mathrm{dH}}{\longrightarrow} \mathrm{d} \mathrm{CH}-\mathrm{CH}=\mathrm{CH}_{2}+2 \mathrm{~d} \mathrm{CO}$<smiles>O=Cc1ccco1</smiles><smiles>C[14CH2]c1ccco1</smiles>

Figure 4 compares the TPD spectra of (a) $\mathrm{H}_{2}$, (b) $\mathrm{CO}$, (c) propylene and (d) 2methylfuran with an exposure of 4L furfural on Ni(111) and ML Fe/Ni(111) surfaces. Furfuryl alcohol (m/e=98) is not observed from the TPD spectra on either Ni(111) or ML Fe/Ni(111) (not 
shown here). As shown in Figure 4a, $\mathrm{H}_{2}$ desorbs from Ni(111) at $390 \mathrm{~K}$ and from ML Fe/Ni(111) at $415 \mathrm{~K}$. In Figure 4b, the desorption peak of $\mathrm{CO}$ from furfural decomposition is observed at $415 \mathrm{~K}$ on $\mathrm{Ni}(111)$ and $380 \mathrm{~K}$ on $\mathrm{ML} \mathrm{Fe} / \mathrm{Ni}(111)$. Figure $4 \mathrm{c}$ is the desorption profile of propylene, from the decarbonylation of furfural, at $270 \mathrm{~K}$ and $315 \mathrm{~K}$ from $\mathrm{Ni}(111)$. The desorption peak area of propylene from the $\mathrm{ML} \mathrm{Fe} / \mathrm{Ni}(111)$ surface is negligible. Figure $4 \mathrm{~d}$ shows the desorption of 2-methylfuran. The production of 2-methylfuran occurs at $325 \mathrm{~K}$ from the ML Fe/Ni(111) surface, but not from $\mathrm{Ni}(111)$, indicating that the addition of ML Fe on $\mathrm{Ni}(111)$ introduces the new deoxygenation pathway for 2-methylfuran production.

The amount of furfural following each reaction pathway is quantified and summarized in Table 2. The details about the quantification method was described previously [29]. On the Ni(111) surface, furfural shows a high reforming activity (0.071) and total activity (0.153). There is no 2-methylfuran production activity on the $\mathrm{Ni}(111)$ surface. With the addition of monolayer Fe on the surface, the reforming activity and total activity of furfural decrease to 0.027 and 0.037 , respectively. Different from the $\mathrm{Ni}(111)$ surface, $\mathrm{ML} \mathrm{Fe} / \mathrm{Ni}(111)$ shows an activity of 0.003 for the desirable 2-methylfuran production.

\subsection{Correlation between DFT and Experimental Results}

It should be pointed out that a detailed comparison of the entire reaction network and activation barriers for the three molecules on $\mathrm{Ni}(111)$ and $\mathrm{ML} \mathrm{Fe} / \mathrm{Ni}(111)$ surfaces would be needed to directly correlate theoretical predictions with experimental results. However, these calculations would be computationally expensive, even for relatively small oxygenate molecules. The primary purpose of the current study is to use relatively simple calculations of binding 
energies and bond lengths of reactants and likely intermediates to help understand experimental results of reaction pathways.

As compared in Table 1, the binding energies of glycolaldehyde, acetaldehyde and furfural on the ML Fe/Ni(111) surface are stronger than those on Ni(111). The difference in the binding energies arises from the different electronic properties in the surfaces. The d-band density of states (DOS) for clean $\mathrm{Ni}(111)$ and $\mathrm{ML} \mathrm{Fe} / \mathrm{Ni}(111)$ surfaces are calculated and compared in Figure 5. The DOS of the clean Ni(111) surface is relatively narrow. With the addition of an Fe layer on top of $\mathrm{Ni}(111)$, the distribution of the d-band states becomes wider. Based on the calculated d-band DOS results, the surface d-band centers for clean $\mathrm{Ni}(111)$ and ML Fe/Ni(111) surfaces are $-1.37 \mathrm{eV}$ and $-0.94 \mathrm{eV}$, respectively. With the addition of an $\mathrm{Fe}$ monolayer on the surface, the surface d-band center shifts closer to the Fermi level, leading to stronger binding energies of the three molecules on ML Fe/Ni(111).

There is a correlation between the adsorption geometry and the activity of the reforming pathway. Based on the TPD quantification results summarized in Table 2, Ni(111) shows higher reforming activity than the $\mathrm{ML} \mathrm{Fe} / \mathrm{Ni}(111)$ surface for all three molecules, indicating that the addition of the $\mathrm{Fe}$ monolayer reduces the reforming pathway that requires facile $\mathrm{C}-\mathrm{C}$ bond cleavage. This is consistent with the DFT calculation results. As shown in Table 1, compared with the gas phase molecules, the $\mathrm{C}-\mathrm{C}$ bond lengths increase when the molecules are adsorbed onto $\mathrm{Ni}(111)$ surface, especially for glycolaldehyde and acetaldehyde. The weakening of the C-C bond should contribute to the high reforming activity on $\mathrm{Ni}(111)$. On the other hand, due to the stronger binding between the molecules and the ML Fe/Ni(111) surface, the bond lengths in the molecules are generally longer than those on the $\mathrm{Ni}(111)$ surface, except for the $\mathrm{C}-\mathrm{C}$ bond lengths. The C-C bond lengths in glycolaldehyde and acetaldehyde as well as the $\mathrm{C} 1-\mathrm{C} 2$ bond 
length in furfural are shorter on ML Fe/Ni(111) than on the $\mathrm{Ni}(111)$ surface. The decrease in those $\mathrm{C}-\mathrm{C}$ bond lengths leads to the suppression in reforming activity on the ML Fe/Ni(111) surface.

Based on the TPD results, on $\mathrm{Ni}(111)$ and $\mathrm{ML} \mathrm{Fe} / \mathrm{Ni}(111)$ surfaces, the adsorbed glycolaldehyde and acetaldehyde molecules mostly follow the reforming pathway to produce syngas. In comparison, as shown in Section 3.4, furfural mainly follows the reforming pathway on $\mathrm{Ni}(111)$. However, with the addition of Fe monolayer onto the surface, the reforming pathway is suppressed and the deoxygenation pathway for the desirable 2-methylfuran production is promoted. The detailed mechanism of furfural reaction on hydrogen-predosed ML Fe/Ni(111) surface has been shown in a previous study, with the increase in the deoxygenation pathway activity of furfural being attributed to the combination of lengthening in the $\mathrm{C}=\mathrm{O}$ carbonyl bond and a slightly tilted furan ring away from the surface [29]. Similar factors might also contribute to the enhanced deoxygenation pathway in the current study, i.e., on $\mathrm{Fe} / \mathrm{Ni}(111)$ without predosed hydrogen atoms.

\section{Conclusions}

In the current work, glycolaldehyde, acetaldehyde and furfural are studied on $\mathrm{Ni}(111)$ and ML Fe/Ni(111) surfaces as model compounds of the three classes of biomass, cellulose, hemicellulose and lignin. The ML Fe/Ni(111) surface is identified as a promising non-precious bimetallic surface for biomass conversion. The addition of Fe monolayer on the Ni(111) surface suppresses the reforming pathway due to a decrease in the $\mathrm{C}-\mathrm{C}$ bond length. The $\mathrm{Fe} / \mathrm{Ni}(111)$ surface also promotes the deoxygenation pathway of furfural resulting from the lengthening of the $\mathrm{C}-\mathrm{O}$ bond of the carbonyl group. 
Acknowledgment

This article was based on work supported as part of the Catalysis Center for Energy Innovation, an Energy Frontier Research Center funded by the U.S. Department of Energy, Office of Science, Office of Basic Energy Sciences under Award Number DE-SC0001004. Additionally, the DFT calculations in this work were performed using computational resources at Center for Functional Nanomaterials, Brookhaven National Laboratory, supported by the U.S. DOE/BES, under Contract No. DE-AC02-98CH10886.

Reference

[1] J.W. Medlin, ACS Catal., 1 (2011) 1284.

[2] W.T. Yu, M.A. Barteau, J.G. Chen, J. Am. Chem. Soc., 133 (2011) 20528.

[3] A.G. Gayubo, B. Valle, A.T. Aguayo, M. Olazar, J. Bilbao, J. Chem. Technol. Biotechnol., 85 (2010) 132.

[4] J.P. Lange, E. van der Heide, J. van Buijtenen, R. Price, ChemSusChem, 5 (2012) 150.

[5] G. Melaet, W.T. Ralston, C.-S. Li, S. Alayoglu, K. An, N. Musselwhite, B. Kalkan, G.A. Somorjai, J. Am. Chem. Soc., 136 (2014) 2260.

[6] A.A. Gokhale, J.A. Dumesic, M. Mavrikakis, J. Am. Chem. Soc., 130 (2008) 1402.

[7] Q. Fu, H. Saltsburg, M. Flytzani-Stephanopoulos, Science, 301 (2003) 935.

[8] Y.A. Ryndin, R.F. Hicks, A.T. Bell, Y.I. Yermakov, J. Catal., 70 (1981) 287.

[9] R.R. Davda, J.W. Shabaker, G.W. Huber, R.D. Cortright, J.A. Dumesic, Appl. Catal. B, 43 (2003) 13.

[10] P.J. Berlowitz, D.W. Goodman, Surf. Sci., 187 (1987) 463.

[11] P.J. Berlowitz, J.E. Houston, J.M. White, D.W. Goodman, Surf. Sci., 205 (1988) 1. 
[12] J.G. Chen, C.A. Menning, M.B. Zellner, Surf. Sci. Rep., 63 (2008) 201.

[13] D.W. Goodman, Ultramicroscopy, 34 (1990) 1.

[14] J.A. Rodriguez, Surf. Sci. Rep., 24 (1996) 225.

[15] W.T. Yu, M.D. Porosoff, J.G. Chen, Chem. Rev., 112 (2012) 5780.

[16] J.R. Kitchin, N.A. Khan, M.A. Barteau, J.G. Chen, B. Yakshinksiy, T.E. Madey, Surf. Sci., 544 (2003) 295.

[17] S. Sitthisa, D.E. Resasco, Catal. Lett., 141 (2011) 784.

[18] S. Sitthisa, W. An, D.E. Resasco, J. Catal., 284 (2011) 90.

[19] G. Kresse, J. Furthmuller, Phys. Rev. B, 54 (1996) 11169.

[20] G. Kresse, J. Hafner, Phys. Rev. B, 47 (1993) 558.

[21] G. Kresse, J. Furthmuller, Comput. Mater. Sci., 6 (1996) 15.

[22] C.M. Ammann, G.A. Meehl, W.M. Washington, C.S. Zender, Geophys. Res. Lett., 30 (2003) 1657.

[23] J.P. Perdew, J.A. Chevary, S.H. Vosko, K.A. Jackson, M.R. Pederson, D.J. Singh, C. Fiolhais, Phys. Rev. B, 46 (1992) 6671.

[24] M.P. Teter, M.C. Payne, D.C. Allan, Phys. Rev. B, 40 (1989) 12255.

[25] M. Salciccioli, W. Yu, M.A. Barteau, J.G. Chen, D.G. Vlachos, J. Am. Chem. Soc., 133 (2011) 7996.

[26] M. Myint, Y. Yan, J.G. Chen, J. Phys. Chem. C, 118 (2014) 11340.

[27] B. An, L. Zhang, S. Fukuyama, K. Yokogawa, Phys. Rev. B, 79 (2009) 085406.

[28] P.J. Cumpson, M.P. Seah, Surf. Interface Anal., 25 (1997) 430.

[29] W. Yu, K. Xiong, N. Ji, M.D. Porosoff, J.G. Chen, J. Catal., 317 (2014) 253.

[30] A. Winkler, Fresenius J. Anal. Chem., 319 (1984) 635. 
[31] F.P. Netzer, T.E. Madey, J. Chem. Phys., 76 (1982) 710.

[32] W.T. Yu, Z.J. Mellinger, M.A. Barteau, J.G. Chen, J. Phys. Chem. C, 116 (2012) 5720. 


\section{Figure and Table Captions}

Figure 1. Top and side views of the optimized configurations of glycolaldehyde, acetaldehyde and furfural on the ML Fe/Ni(111) surface (Ni: iceblue, Fe: aqua, C: grey, O: red, H: white).

Figure 2. TPD spectra of (a) hydrogen $(\mathrm{m} / \mathrm{e}=2)$ and (b) $\mathrm{CO}(\mathrm{m} / \mathrm{e}=28)$ with an exposure of $4 \mathrm{~L}$ glycolaldehyde on $\mathrm{Ni}(111)$ and ML Fe/Ni(111) surfaces.

Figure 3. TPD spectra of (a) hydrogen and (b) CO following $4 \mathrm{~L}$ acetaldehyde exposure on $\mathrm{Ni}(111)$ and ML Fe/Ni(111) surfaces.

Figure 4. TPD spectra of (a) hydrogen $(\mathrm{m} / \mathrm{e}=2)$, (b) CO $(\mathrm{m} / \mathrm{e}=28)$, (c) propylene $(\mathrm{m} / \mathrm{e}=41)$ and (d) 2-methylfuran $(\mathrm{m} / \mathrm{e}=53)$ with an exposure of $4 \mathrm{~L}$ furfural on $\mathrm{Ni}(111)$ and $\mathrm{ML} \mathrm{Fe} / \mathrm{Ni}(111)$ surfaces.

Figure 5. DFT calculated d-band density of states for Ni(111) and ML Fe/Ni(111) surfaces.

Table 1. Surface d-band centers (eV) of Ni(111) and ML Fe/Ni(111) surfaces as well as the comparison of bond lengths (in Á) and binding energies (BE) (in kcal/mol) of glycolaldehyde, acetaldehyde and furfural in gas phase and adsorbed on corresponding surfaces

Table 2. Reaction activity of glycolaldehyde, acetaldehyde and furfural on Ni(111) and ML $\mathrm{Fe} / \mathrm{Ni}(111)$ surfaces from TPD measurements 

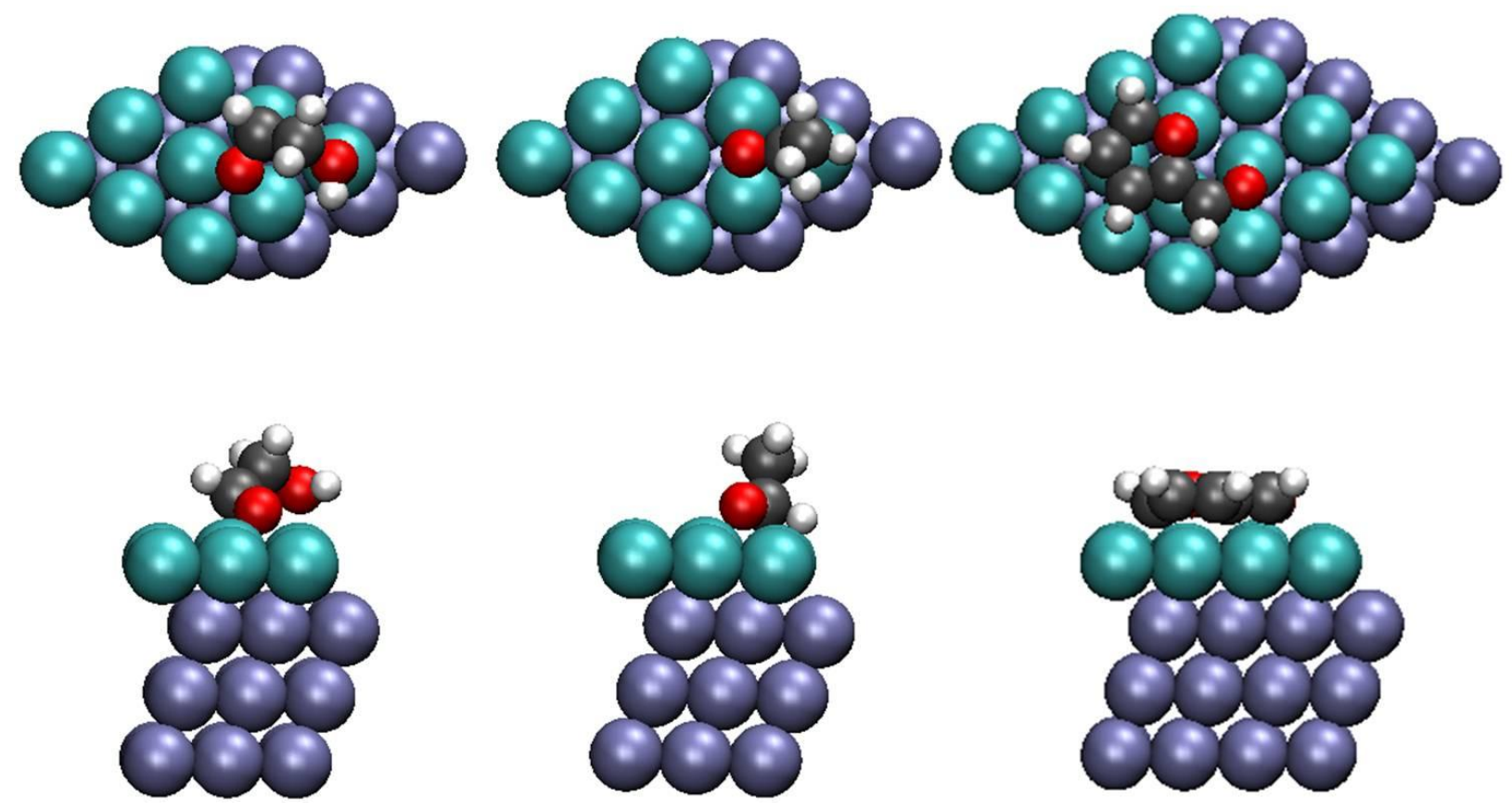

Figure 1. Top and side views of the optimized configurations of glycolaldehyde, acetaldehyde and furfural on the ML Fe/Ni(111) surface (Ni: iceblue, Fe: aqua, C: grey, O: red, H: white). 

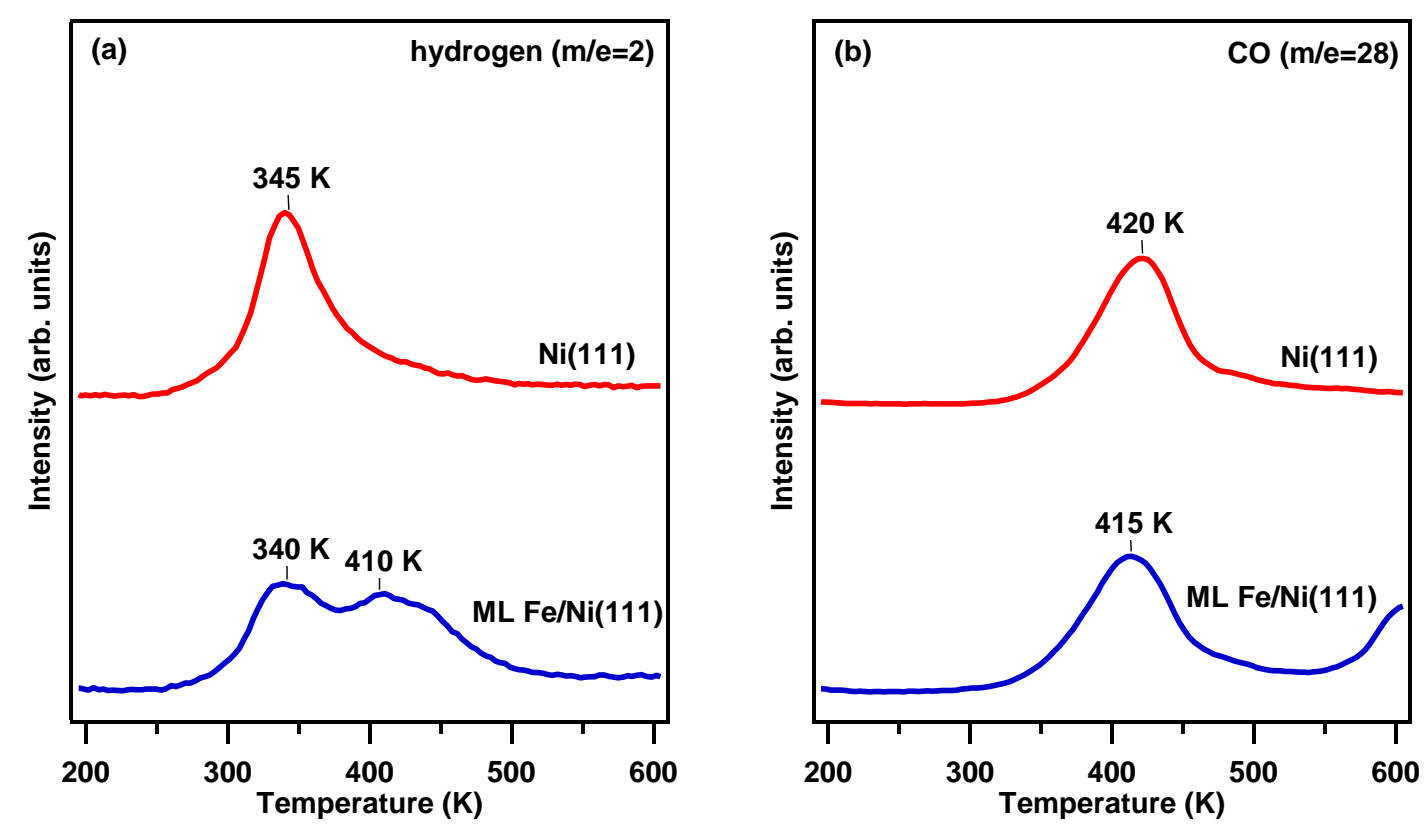

Figure 2. TPD spectra of (a) hydrogen $(\mathrm{m} / \mathrm{e}=2)$ and (b) $\mathrm{CO}(\mathrm{m} / \mathrm{e}=28)$ with an exposure of $4 \mathrm{~L}$ glycolaldehyde on $\mathrm{Ni}(111)$ and $\mathrm{ML} \mathrm{Fe} / \mathrm{Ni}(111)$ surfaces. 

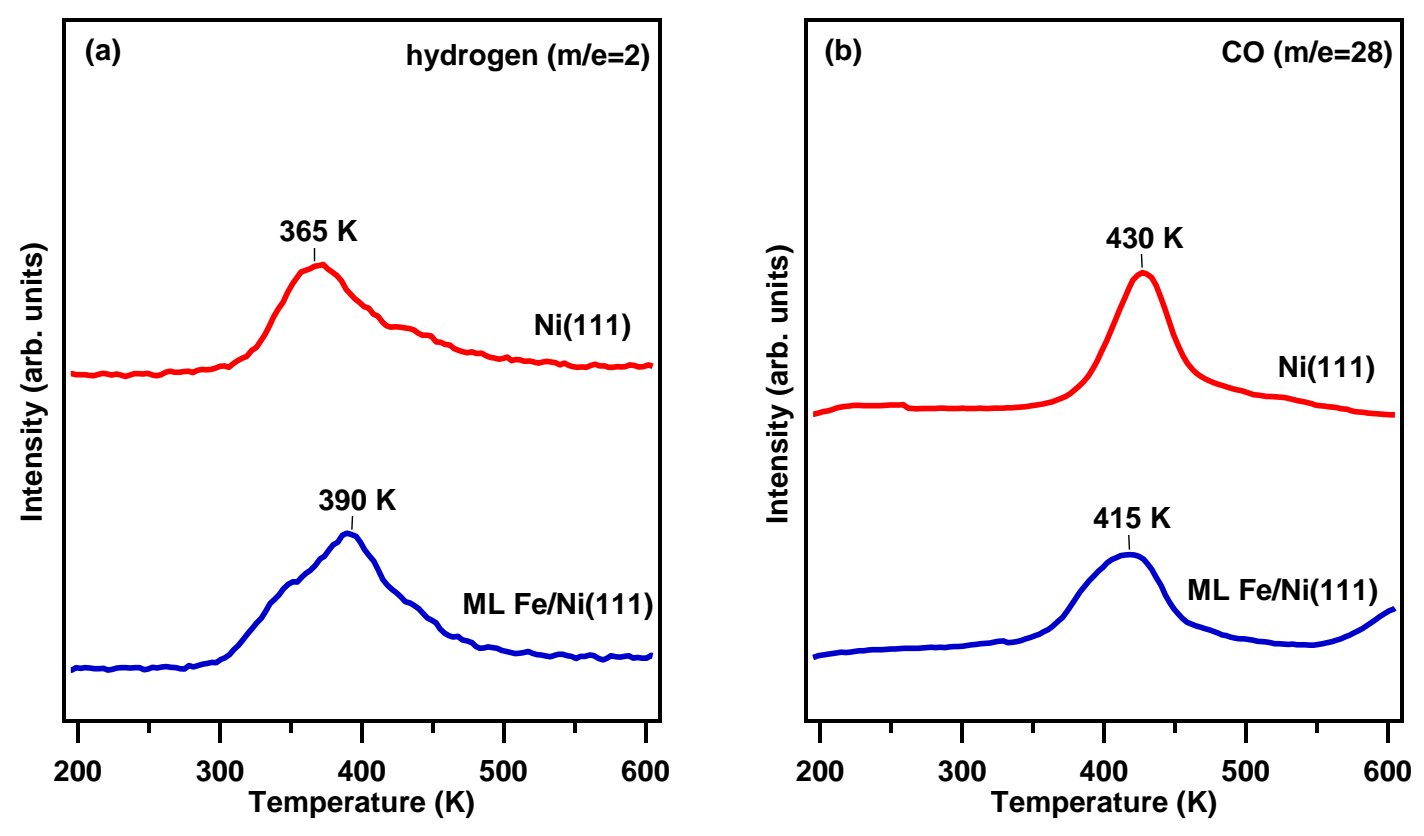

Figure 3. TPD spectra of (a) hydrogen and (b) CO following $4 \mathrm{~L}$ acetaldehyde exposure on $\mathrm{Ni}(111)$ and $\mathrm{ML} \mathrm{Fe} / \mathrm{Ni}(111)$ surfaces. 

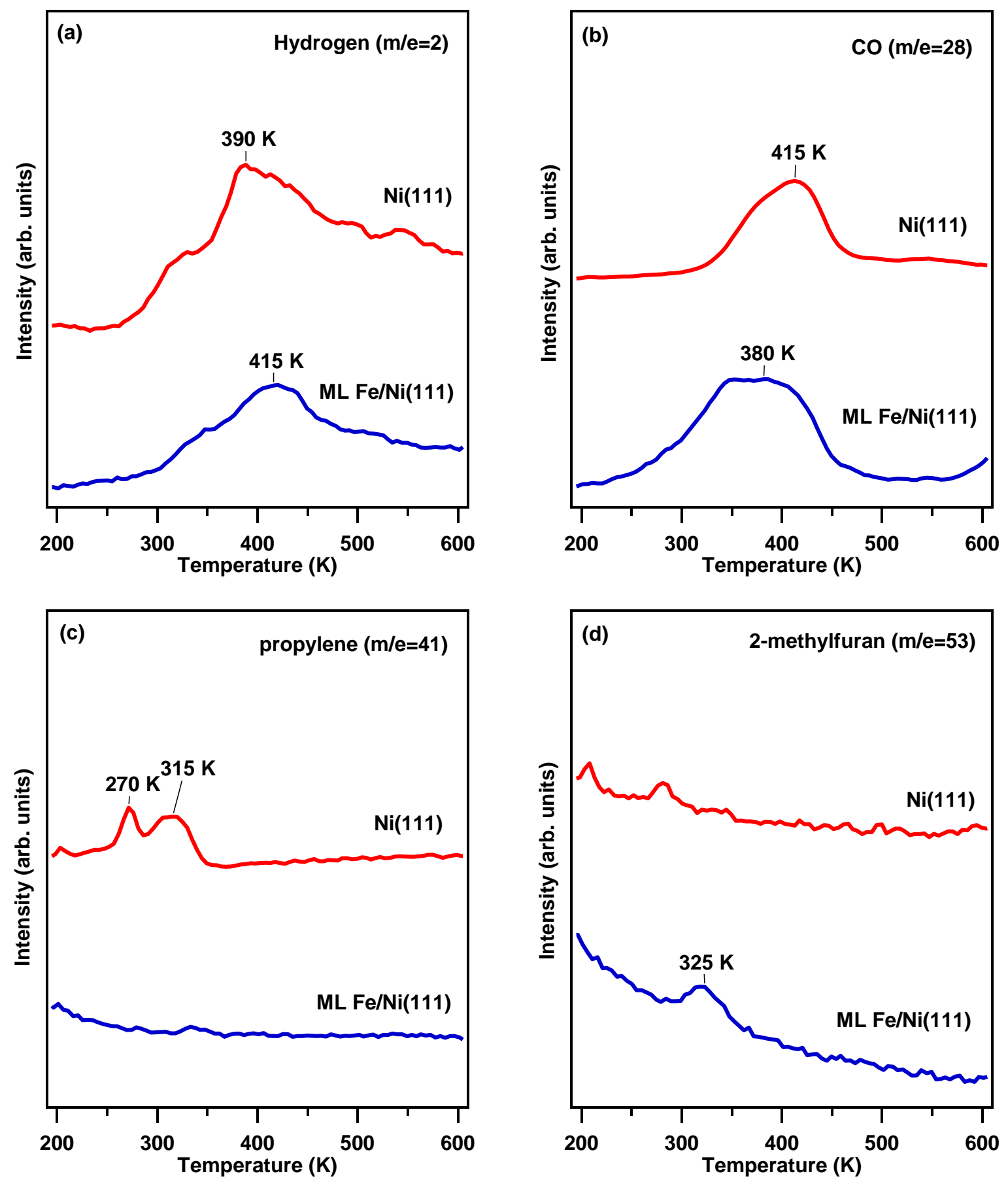

Figure 4. TPD spectra of (a) hydrogen $(\mathrm{m} / \mathrm{e}=2)$, (b) CO $(\mathrm{m} / \mathrm{e}=28)$, (c) propylene $(\mathrm{m} / \mathrm{e}=41)$ and (d) 2-methylfuran $(\mathrm{m} / \mathrm{e}=53)$ with an exposure of $4 \mathrm{~L}$ furfural on $\mathrm{Ni}(111)$ and $\mathrm{ML} \mathrm{Fe} / \mathrm{Ni}(111)$ surfaces. 


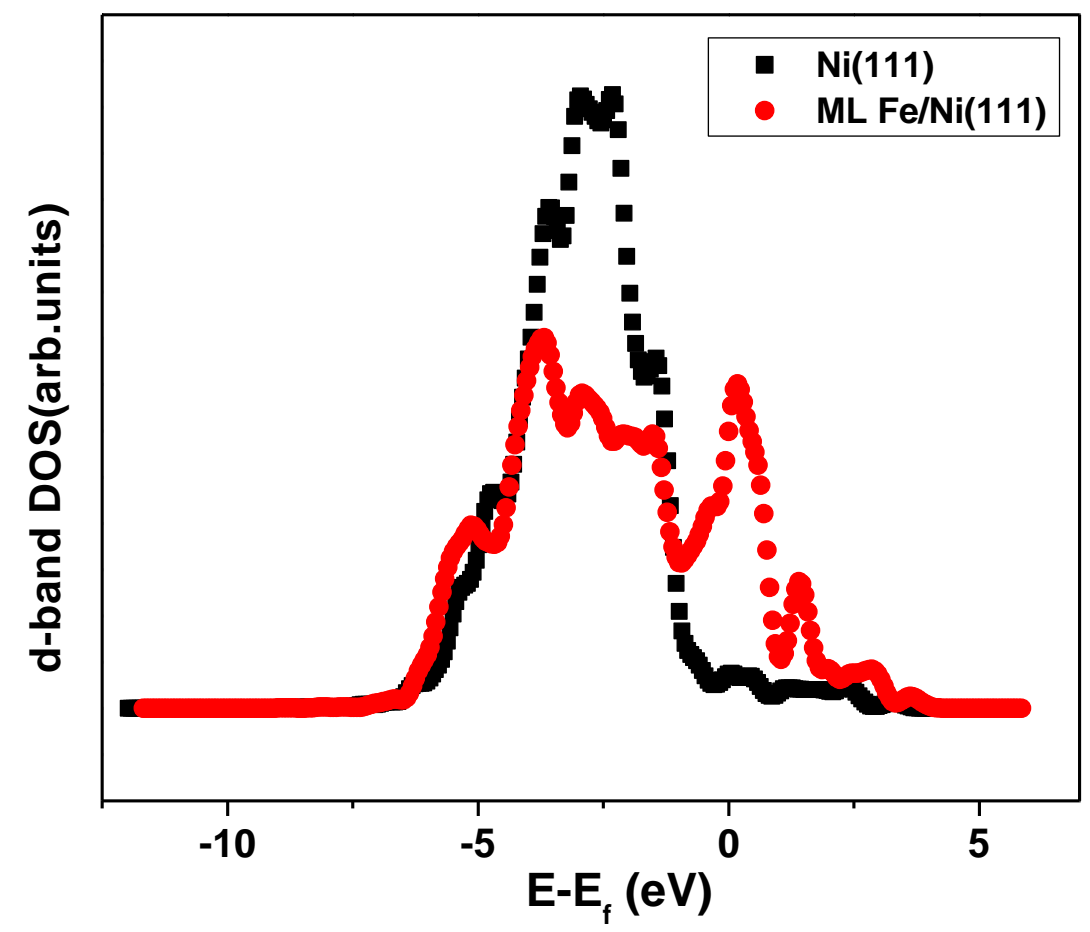

Figure 5. DFT calculated d-band density of states for Ni(111) and ML Fe/Ni(111) surfaces. 
Table 1. Surface d-band centers (eV) of $\mathrm{Ni}(111)$ and ML Fe/Ni(111) surfaces as well as the comparison of bond lengths (in Á) and binding energies (BE) (in kcal/mol) of glycolaldehyde, acetaldehyde and furfural in gas phase and adsorbed on corresponding surfaces

\begin{tabular}{|c|c|c|c|c|}
\hline & & Gas phase & $\mathrm{Ni}(111)$ & ML Fe/Ni(111) \\
\hline d-band center & & 1 & -1.37 & -0.94 \\
\hline \multirow{4}{*}{ Glycolaldehyde } & $\mathrm{BE}$ & I & -11.100 & -27.500 \\
\hline & $\mathrm{C}=\mathrm{O}$ & 1.226 & 1.350 & 1.408 \\
\hline & $\mathrm{C}-\mathrm{O}$ & 1.401 & 1.448 & 1.453 \\
\hline & $\mathrm{C}-\mathrm{C}$ & 1.504 & 1.513 & 1.494 \\
\hline \multirow{3}{*}{ Acetaldehyde } & $\mathrm{BE}$ & I & -5.861 & -13.550 \\
\hline & $\mathrm{C}=\mathrm{O}$ & 1.220 & 1.325 & 1.354 \\
\hline & $\mathrm{C}-\mathrm{C}$ & 1.495 & 1.501 & 1.500 \\
\hline \multirow{3}{*}{ Furfural } & $\mathrm{BE}$ & I & -20.337 & -31.609 \\
\hline & $\mathrm{C} 1-\mathrm{O} 1$ & 1.229 & 1.320 & 1.340 \\
\hline & $\mathrm{C} 1-\mathrm{C} 2$ & 1.448 & 1.435 & 1.422 \\
\hline \multirow{5}{*}{ } & $\mathrm{C} 2-\mathrm{C} 3$ & 1.382 & 1.433 & 1.430 \\
\hline & $\mathrm{C} 3-\mathrm{C} 4$ & 1.419 & 1.425 & 1.440 \\
\hline & $\mathrm{C} 4-\mathrm{C} 5$ & 1.373 & 1.449 & 1.449 \\
\hline & $\mathrm{C} 5-\mathrm{O} 2$ & 1.359 & 1.474 & 1.471 \\
\hline & $\mathrm{O} 2-\mathrm{C} 2$ & 1.378 & 1.409 & 1.414 \\
\hline
\end{tabular}


Table 2. Reaction activity of glycolaldehyde, acetaldehyde and furfural on Ni(111) and ML $\mathrm{Fe} / \mathrm{Ni}(111)$ surfaces from TPD measurements

\begin{tabular}{|c|c|c|c|c|c|c|}
\hline \multicolumn{7}{|c|}{ Activity (monolayer per metal atom) } \\
\hline & & Decomposition & Reforming & Deoxygenation & Decarbonylation & $\begin{array}{c}\text { Total } \\
\text { activity }\end{array}$ \\
\hline \multirow{2}{*}{ Glycolaldehyde } & $\mathrm{Ni}(111)$ & 0.047 & 0.146 & - & - & 0.193 \\
\hline & ML Fe/Ni(111) & 0.033 & 0.116 & - & - & 0.149 \\
\hline \multirow{2}{*}{ Acetaldehyde } & $\mathrm{Ni}(111)$ & 0.005 & 0.157 & - & - & 0.162 \\
\hline & ML Fe/Ni(111) & 0.000 & 0.104 & - & - & 0.104 \\
\hline \multirow{2}{*}{ Furfural } & $\mathrm{Ni}(111)$ & 0.079 & 0.071 & 0.000 & 0.003 & 0.153 \\
\hline & ML Fe/Ni(111) & 0.007 & 0.027 & 0.003 & 0.000 & 0.037 \\
\hline
\end{tabular}

